\title{
Role of the Bordetella pertussis P.69/pertactin protein and the P.69/pertactin RGD motif in the adherence to and invasion of mammalian cells
}

\author{
Paul Everest, ${ }^{1}$ Jingli Li, ${ }^{2}$ Gillian Douce, ${ }^{1}$ lan Charles, ${ }^{3}$ Joyce De Azavedo, ${ }^{3} \dagger$ \\ Steven Chatfield, ${ }^{2}$ Gordon Dougan ${ }^{1}$ and Mark Roberts ${ }^{4}$
}

\footnotetext{
1,2 Department of Biochemistry ${ }^{1}$ and Vaccine Research Unit, Medeva, Department of Biochemistry², Imperial College of Science, Technology and Medicine, London SW7 2AZ, UK

3 Department of Cell Biology, Wellcome Research Laboratories, Beckenham, Kent BR3 3BS, UK

4 Department of Veterinary Pathology, Glasgow University Veterinary School, Bearsden, Glasgow G61 1QH, UK
}

\author{
Author for correspondence: Mark Roberts. Tel: +441413305780 . Fax: +441413305602. \\ e-mail: gvpa29@udcf.gla.ac.uk
}

Keywords: Bordetella pertussis, pertactin, RGD motif, adhesion, invasion

\begin{abstract}
The role of the Bordetella pertussis P.69/pertactin protein in mammalian cell adhesion and invasion was investigated. Salmonella strains expressing surface-associated P.69/pertactin from a chromosomally located prn gene were significantly more invasive than isogenic parental strains. This effect was most pronounced in the poorly invasive, semi-rough S. typhimurium strain LB5010. Escherichia coli K-12 strain HB101 harbouring the plasmid p41869D, which encodes the full-length prn gene under the control of the tac promoter on the broad-host-range plasmid pMMB66EH, was significantly more adhesive to HEp-2 and Chinese Hamster Ovary (CHO) cells growing in culture than E. colf HB101(pMMB66EH). However, the ability of E. colf to invade mammalian cells was not affected by P.69/pertactin expression. P.69/pertactin-mediated adhesiveness of HB101 to HEp-2 and CHO cells was not influenced by the viability of the bacterial cells. However, adherence was markedly reduced when assays were performed for less than $3 \mathrm{~h}$, at $4^{\circ} \mathrm{C}$ or in the presence of cycloheximide, suggesting the active participation of the eukaryotic cell in bacterial adhesion. Site-directed mutagenesis was used to mutate Asp to Glu in an Arg-Gly-Asp (RGD $\rightarrow R G E$ ) sequence present in mature P.69/pertactin and the mutated gene was cloned in the same broad-host-range vector (plasmid p41869E). This mutation had no detectable influence on the ability of P.69/pertactin to mediate adhesion of HB101 to HEp-2 or CHO cells. Plasmids P41869D and P41869E were introduced into the bvg-negative B. pertussis strain BP347. Expression of P.69RGD or P.69RGE did not enhance the adhesiveness of BP347 for epithelial (HEp-2 and CHO) cells.
\end{abstract}

\section{INTRODUCTION}

Bordetella pertussis, the causative agent of whooping cough, colonizes the respiratory tract mucosa of the host by adhering to host tissues, in particular ciliated epithelial cells and possibly alveolar macrophages (Tuomanen \& Weiss, 1985; Rappuoli, 1994; Friedman et al., 1992). A number of bacterial surface-associated proteins, including fimbriae (Mooi et al., 1992), filamentous haemagglutinin

† Present address: The Samuel Luenfield Research Institute, Mount Sinai Hospital, Toronto, Canada.

Abbreviations: CHO, Chinese Hamster Ovary; FACS, fluorescenceactivated cell sorting; FHA, filamentous haemagglutinin; FITC, fluorescein isothiocyanate; SDM, site-directed mutagenesis.
(FHA; Tuomanen \& Weiss, 1985; Relman et al., 1989, 1990; Arico et al., 1993; Locht et al., 1993; Sandros \& Tuomanen, 1993), pertussis toxin (Tuomanen $\&$ Weiss, 1985) and pertactin (Leininger et al., 1991, 1992; Roberts et al., 1991; Arico et al., 1993) have been implicated in the adhesion process. Indeed, several proteins may cooperate to increase the efficiency of adhesion and hence colonization (Rappuoli, 1994). FHA is a large filamentous protein that has both a secreted and cell-associated form and is involved in adherence to ciliated and non-ciliated cells (Tuomanen \& Weiss, 1985; Relman et al., 1989, 1990; Arico et al., 1993; Locht et al., 1993; Sandros \& Tuomanen, 1993). FHA appears to contain multiple adhesive domains, including an Arg-Gly-Asp (RGD) sequence that may target receptors at the surface of 
macrophages (Relman et al., 1990; Locht et al., 1993; Sandros \& Tuomanen, 1993). The sequence RGD has been implicated in the interactions of a number of extracellular matrix proteins such as fibronectin and vitronectin with integrin receptors on the surface of eukaryotic cells (Hynes, 1987).

B. pertussis pertactin, also known as P.69/pertactin after the apparent molecular mass of the mature polypeptide in SDS-polyacrylamide gels (Makoff et al., 1990), has also been implicated in attachment to and invasion of eukaryotic cells (Leininger et al., 1991, 1992; Roberts et al., 1991; Arico et al., 1993). The B. pertussis pertactin gene, prn, encodes a polypeptide of $93000 \mathrm{Da}$ that is processed to yield the polypeptides P.69, derived from the amino-terminus, and P.30, derived from the carboxyterminus (Charles et al., 1989, 1994; Makoff et al., 1990). Both P. 69 and P. 30 can be detected in the outer membrane of cells of $B$. pertussis and enteric bacteria expressing the prn gene (Charles et al., 1994). P.69/pertactin has been used as a subunit vaccine and as a component in a live Salmonella-based vaccine to protect mice against respiratory tract infection by virulent B. pertussis (Shahin et al., 1990; Romanos et al., 1991; Roberts et al., 1992, 1993; Strugnell et al., 1992; Novotny et al., 1991; Anderson et al., 1996). P.69/pertactin has recently been shown to be a critical component of effective acellular whooping cough antigens in humans (Marwick, 1996; Poland, 1996).

The mechanism by which P.69/pertactin mediates adhesion to human cells is poorly understood. No receptor has been identified to date. However, sequencing of the prn gene revealed a number of interesting features in the primary amino acid sequence (Charles et al., 1989). P.69/pertactin contains two regions of repeated amino acid sequences that are immunodominant in the sense that several anti-pertactin $\mathrm{mAbs}$ and polyvalent antibodies recognize the repeat regions (Charles et al., 1991). P.93/pertactin possesses two RGD sequences, although only one is present in the mature P.69 polypeptide, at residues 225-227 from the amino-terminus (Charles $e t a l$., 1989; Makoff et al., 1990).

The role of P.69/pertactin in adherence of $B$. pertussis to cultured mammalian cells has been investigated by constructing defined mutants of $B$. pertussis lacking expression of P.69/pertactin, FHA or both these proteins (Arico et al., 1993; Leininger et al., 1991; Roberts et al., 1991). A role for P.69/pertactin in adherence to HEp-2 cells could only be demonstrated in the absence of FHA expression (Arico et al., 1993; Roberts et al., 1993). Experiments using Chinese Hamster Ovary (CHO) and HeLa cells showed a 30-40\% reduction in adherence of P.69/pertactin-deficient mutants (Leininger et al., 1991). Studies using purified P.69/pertactin have implicated a role for the RGD sequence in attachment as synthetic peptides corresponding to the RGD sequence can partially inhibit bacterial adhesion to eukaryotic target cells (Leininger et al., 1991, 1992). Interestingly, synthetic peptide inhibition studies suggested that the P.69/ pertactin RGD sequence may play a role in the entry of $B$. pertussis into HeLa cells (Leininger et al., 1992). In this report, we describe further studies on the interaction of
P.69/pertactin with mammalian cells using different bacterial species expressing surface-associated P.69/ pertactin.

\section{METHODS}

Bacterial strains, plasmids and growth conditions. Escherichia coli K-12 HB101 (Davis et al., 1980) was used for propagation of plasmids directing P.69/pertactin expression. Salmonella typhimurium strain BRD641 is a derivative of LB5010 harbouring a single copy of the full-length prn gene integrated into the Salmonella chromosome at the aroC locus (Strugnell et al., 1992). P.69/pertactin is expressed at the bacterial cell surface from the trc promoter in this strain. S. typhimurium strain BRD640 is a derivative of BRD509 (aro $A$ aroD) constructed by transducing the aroC::prn locus of BRD641 into BRD509 using bacteriophage-P22-mediated transduction (Strugnell et al., 1992). The construction of BRD641 and BRD640 has been described previously by Strugnell et al. (1992). E. coli HB101(pR1203) expresses the Yersinia pseudotuberculosis invasin protein at its surface (Isberg \& Falkow, 1996).

E. coli and Salmonella strains were grown in L-broth or on L-agar (Davis et al., 1980) supplemented with antibiotics as appropriate. Antibiotics were used at a concentration of $100 \mu \mathrm{g} \mathrm{m}^{-1}$. Minimal medium was prepared as described by Cohen \& Wheeler (1946). B. pertussis strains were cultured on CohenWheeler agar (Cohen \& Wheeler, 1946) supplemented with $10 \%(\mathrm{v} / \mathrm{v})$ defibrinated horse blood and antibiotics as appropriate. BP536 is a streptomycin-tesistant detivative of $B$. pertussis Tohama 1 (Relman et al., 1989) and BP347 is a Tn5induced bvg-negative mutant of Tohama 1 (Weiss et al., 1983).

Plasmid pPERtac36 is a vector that encodes P.69/pertactin (Makoff et al., 1990); pAYL1 encodes P.93/pertactin (Charles $e t$ al., 1994). Plasmid pMMB66EH is a broad-host-range Ptac expression vector (Furste et al., 1986).

Construction of RGD to RGE (Arg-Gly-Glu) site-directed mutants of prn and broad-host-range vectors that express wild-type and mutant pertactin. A $753 \mathrm{bp} A c c \mathrm{I}$ fragment flanking the RGD site of P.69/pertactin was isolated and subcloned in M13mp19 for site-directed mutagenesis (SDM) (Fig. 1). SDM was carried out using a mutagenesis kit supplied by Amersham and the oligonucleotide $5^{\prime}$-ATA GCG CGC GGG GAG GCG CCT GCC-3'. Following mutagenesis, the RGD to RGE site-directed change was confirmed by DNA sequencing, and the mutated $A c c \mathrm{I}$ fragment was isolated and subcloned into $A c c$ I-digested pPER tac36 (Makoff et al., 1990) to generate $\mathrm{pPERtac} 36(\mathrm{E})$. In order to generate a vector capable of directing the expression of full-length P.93/pertactin to the bacterial cell surface, a $S m a I-S a c I$ fragment of pPERtac36(E) was gel-purified and ligated with SmaI-SacI pAYL1 to generate pAYL1(E). The whole P.93/pertactin gene can be conveniently excised as a BamHI fragment from either the native (pAYL1) or mutant [pAYL1(E)] plasmids and ligated into the broad-hostrange expression vector $\mathrm{pMMB} 66 \mathrm{EH}$ to generate either p41869D (expressing RGD-containing P.93) or p41869E (expressing RGE-containing P.93). Plasmids $\mathrm{p} 41869 \mathrm{D}$ and p41869E were introduced into E. coli $\mathrm{HB} 101$ and B. pertussis BP347 by electroporation. Expression of P.69/pertactin was analysed with a P.69/pertactin-specific $\mathrm{mAb}(\mathrm{BB} 05)$ by Western blotting to determine the level of expression and by agglutination to determine if P.69/pertactin was surface-exposed as previously described by Strugnell et al. (1992). All strains containing plasmids expressing pertactin produced similar levels of P.69/pertactin and were readily agglutinated by the pertactinspecific $\mathrm{mAb}$ (data not shown). 

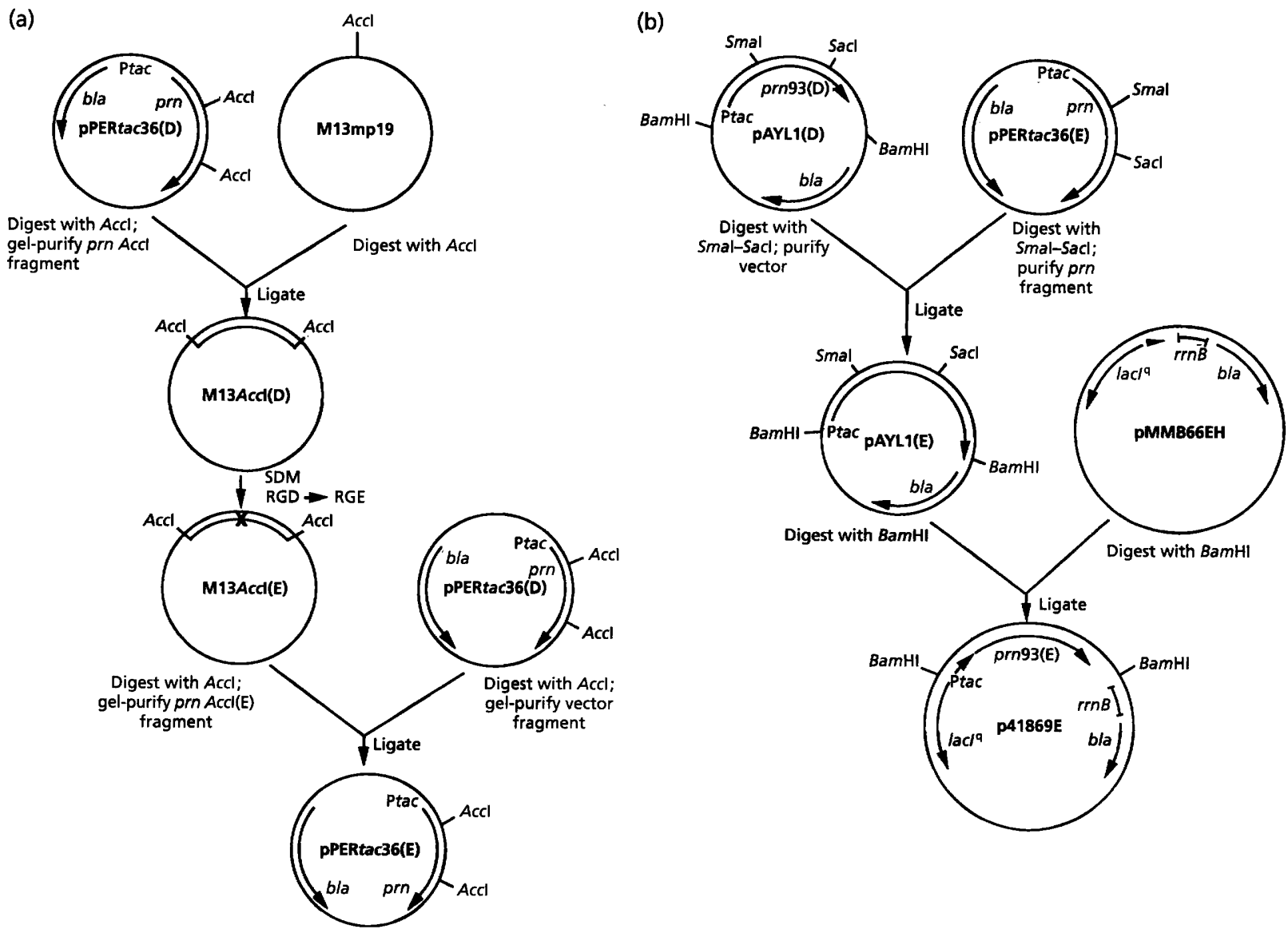

Fig. 1. SDM of prn (a) and cloning of the mutant prn into a broad-host-range vector (b). A fragment of prn encoding the RGD site was subcloned into M13mp19 and SDM was performed so that the fragment would now encode RGE. The mutagenized fragment was swapped with the equivalent fragment in the wild-type gene. The mutant prn gene was cloned into the broad-host-range vector PMMB66EH. A full description of the mutagenesis and cloning are given in Methods. The letters in parentheses following the plasmid name denote whether the prn gene is wild-type (D, RGD) or mutant (E, RGE).

Cell adhesion and invasion assays. For adhesion assays, HEp2 and $\mathrm{CHO}$ cells were used. These cells were cultured in Dulbecco's Modified Eagle Medium (DMEM) medium containing $10 \%(\mathrm{v} / \mathrm{v})$ foetal calf serum and $2 \mathrm{mM}$ glutamate (Sigma) at $37^{\circ} \mathrm{C}$ in an atmosphere containing $5 \% \mathrm{CO}_{2}$. For adhesion and invasion assays, cells were seeded into 24 -well tissue culture plates (Costar). When the monolayers were confluent $\left(\sim 2 \times 10^{5}\right.$ cells per well), bacterial strains were added to the cells at a concentration of $1 \times 10^{7}$ and $E$. coli and $B$. pertussis, but not Salmonella, were centrifuged at $300 \mathrm{~g}$ onto the cell monolayer. The monolayers were incubated for at least $3 \mathrm{~h}$ at $37^{\circ} \mathrm{C}$ in an atmosphere of $5 \% \mathrm{CO}_{2}$ and were then washed at least five times with PBS (Dulbecco's, with calcium and magnesium; Sigma; $\mathrm{pH} 7 \cdot 2$ ). The monolayers were then lysed using $1 \%(\mathrm{v} / \mathrm{v})$ Triton $\mathrm{X}-100$ in PBS for Salmonella and E. coli strains and with $\mathrm{H}_{2} \mathrm{O}$ and vigorous pipetting for $B$. pertussis (Roberts et al., 1991). Bacterial viable counts were then determined. Invasion assays were performed in a similar manner except that gentamicin $\left(200 \mu \mathrm{g} \mathrm{ml}^{-1}\right)$ was added for $1 \mathrm{~h}($ Salmonella and $E$. coli) or $3 \mathrm{~h}$ (B. pertussis) after the initial incubation step, followed by washing to remove antibiotic, prior to cell monolayer lysis. In each assay, every strain was tested in at least triplicate.
Determination of bacterial adhesion using fluorescenceactivated cell sorting (FACS). Bacterial cells were labelled using fluorescein isothiocyanate (FITC; Sigma). FITC was coupled to washed bacteria grown overnight in broth or on plates by dissolving FITC $\left(1 \mathrm{mg} \mathrm{ml}^{-1}\right)$ in dimethyl sulphoxide and adding $1 \times 10^{7}$ bacteria and incubating for $4 \mathrm{~h}$ at $37^{\circ} \mathrm{C}$. The FITClabelled bacteria were washed extensively in PBS and added to tissue-culture-grown eukaryotic cells in a 24-well plate (Costar). The cells were centrifuged at $300 \mathrm{~g}$ for $30 \mathrm{~min}$ and incubated at $37^{\circ} \mathrm{C}$ for $3 \mathrm{~h}$. The cells were then washed at least five times in PBS and incubated in cell dissociation solution (Sigma). FITClabelled bacteria adhering to tissue culture cells were analysed using a FACSort (Becton Dickinson).

Bacterial adhesion ELISA. HEp- 2 or $\mathrm{CHO}$ cells were grown to confluence in Costar flat-bottomed 96-well plates. The wells were then blocked using $1 \%(\mathrm{w} / \mathrm{v})$ bovine serum albumin in DMEM and different numbers of test bacteria were added to the wells. The plates were centrifuged at $300 \mathrm{~g}$ for $30 \mathrm{~min}$ and incubated at $37^{\circ} \mathrm{C} / 5 \% \mathrm{CO}_{2}$ for $3 \mathrm{~h}$. The wells were then washed thoroughly with PBS and fixed in $0.2 \%$ glutaraldehyde. Appropriately diluted rabbit anti-E. coli or rabbit anti-wholecell $B$. pertussis sera was added and incubated overnight at $4{ }^{\circ} \mathrm{C}$. The following morning, the wells were washed with PBS 
containing $0 \cdot 05 \%$ Tween 20 and anti-rabbit immunoglobulinhorseradish peroxidase conjugate (Sigma) was added $(1: 1000)$. Following incubation and washing, bound antibodies were visualized by addition of $o$-phenylenediamine (OPD) substrate $(0.04 \%$ OPD in citrate/phosphate buffer, $\mathrm{pH} 5$, containing $\left.0.01 \% \mathrm{H}_{2} \mathrm{O}_{2}\right)$. After colour development, the reaction was stopped with $3 \mathrm{M} \mathrm{H}_{2} \mathrm{SO}_{4}$ and the $A_{490}$ was read (Ceres $900 \mathrm{HDi}$ ELISA plate reader; Bio_tek Instruments).

\section{RESULTS}

\section{Invasion of HEp-2 cells by S. typhimurium expressing surface-associated P.69/pertactin}

S. typhimurium strains BRD640 and BRD641 express surface-associated P.69/pertactin that can be detected using immunoelectron microscopy or agglutination (Strugnell et al., 1992). S. typbimurium LB5010 and BRD509 are the parental strains of BRD641 and BRD640, respectively. HEp-2 invasion assays were performed in order to determine the influence, if any, of P.69/pertactin expression on the mammalian cell invasiveness of the Salmonella strains. Typical results are shown in Fig. 2. Expression of the pertactin gene significantly $(P<0.05)$ enhanced the invasiveness of both $S$. typhimurium strains. LB5010 is a semi-rough strain and is poorly invasive for HEp-2 cells. In different experiments, BRD641 was between 40 and 70 times more invasive than LB5010. BRD509 is naturally much more invasive for HEp-2 cells than LB5010. Nevertheless, expression of P.69/pertactin could still significantly improve the invasiveness of BRD509. Thus, in two different $S$. typhimurium background strains, the expression of surface-associated P.69/ pertactin enhanced entry into HEp-2 cells.

\section{Adherence to and invasion of HEp-2 cells by $E$. coli HB101 expressing surface-associated P.69/pertactin}

Since Salmonella strains are both adhesive and invasive for HEp-2 cells, it is difficult to distinguish whether P.69/

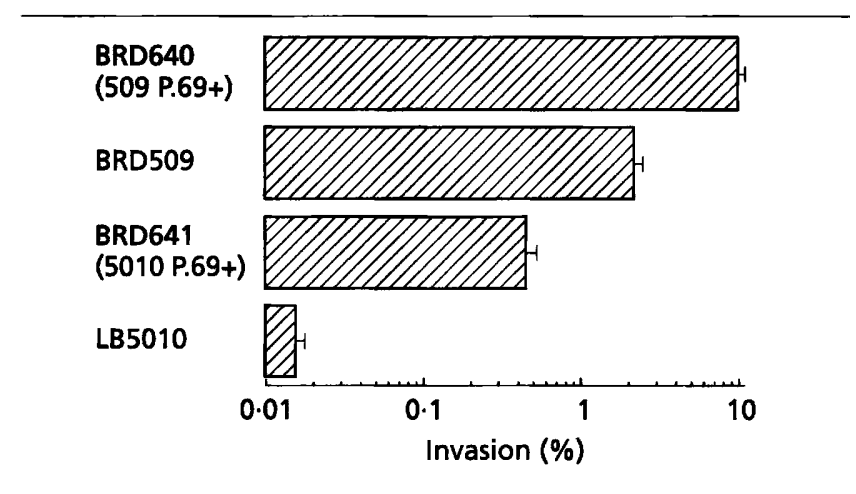

Fig. 2. Invasion of HEp-2 cells by $S$. typhimurium strains expressing P.69/pertactin. Bacteria were added to cells and incubated for $3 \mathrm{~h}$. Cells were washed to remove unbound bacteria and then incubated in the presence of gentamicin to kill extracellular micro-organisms. Intracellular bacteria were enumerated by performing viable counts on cell lysates. The percentage of organisms recovered compared to the initial inoculum was determined. The columns represent the mean percentage invasion of organisms from three separate wells and the error bars represent the SEM.

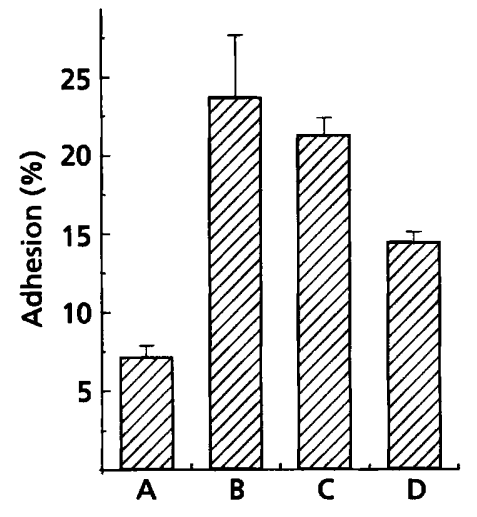

Fig. 3. Adhesion of $E$. coli HB101 expressing P.69/pertactin RGD, P.69/pertactin RGE or invasin to HEp-2 cells. Bacteria were centrifuged onto cells for $30 \mathrm{~min}$ and then incubated at $37^{\circ} \mathrm{C}$ for $3 \mathrm{~h}$ in $10 \% \mathrm{CO}_{2}$. Cells were lysed and the number of cellassociated bacteria was determined by viable count. The percentage of organisms recovered compared to the initial inoculum was determined. The columns represent the mean percentage adhesion of bacteria from four separate wells and the error bars represent the SEM. A, HB101(pMMB66EH); B, HB101(p41869D) (P.69RGD); C, HB101(p41869E) (P.69RGE); D, HB101(pRI203) (invasin protein).

pertactin is promoting adhesion, invasion or both. To address this question, P.69/pertactin was expressed in the poorly adhesive $E$. coli $\mathrm{K}-12$ strain HB101. High-level expression of P.93 is toxic to E. coli (Charles et al., 1994). To overcome this, the prn gene was cloned into the lowcopy-number broad-host-range expression vector pMMB66EH (Fig. 1). E. coli HB101 harbouring the resulting plasmid (p41869D) was readily agglutinated by an anti-pertactin $\mathrm{mAb}$ (data not shown), indicating that P.69/pertactin was located on the cell surface.

HB101(p41869D) was much more adhesive to HEp-2 cells than HB101 harbouring the control vector plasmid pMMB66EH $(P<0.05)$. This difference could be consistently measured by using normal tissue culture cell adhesion assays based on viable counts (Fig. 3) or by using FACS analysis with FITC-labelled E. coli (Fig. 4a). Identical results were seen using $\mathrm{CHO}$ cells (Fig. $4 \mathrm{~b}$ and data not shown).

\section{Role of the RGD site of P.69/pertactin in bacterial adherence}

A mutant form of the prn gene which expressed P.69/ pertactin containing RGE instead of RGD was constructed as described in Methods using SDM of a fragment of the prn gene that included the region encoding the RGD motif. A restriction fragment carrying the mutated prn region was swapped with the equivalent fragment on pAYL1 to create the plasmid p41869E (Fig. 1). HB101(p41869E) synthesized equivalent levels of P.69/pertactin to HB101(p41869D), as determined by Western blotting and agglutination. HB101(p41869E) and HB101(p41869D) were found to possess indistinguishable levels of adhesiveness to HEp-2 cells when assayed using viable counts or using FACS analysis. 


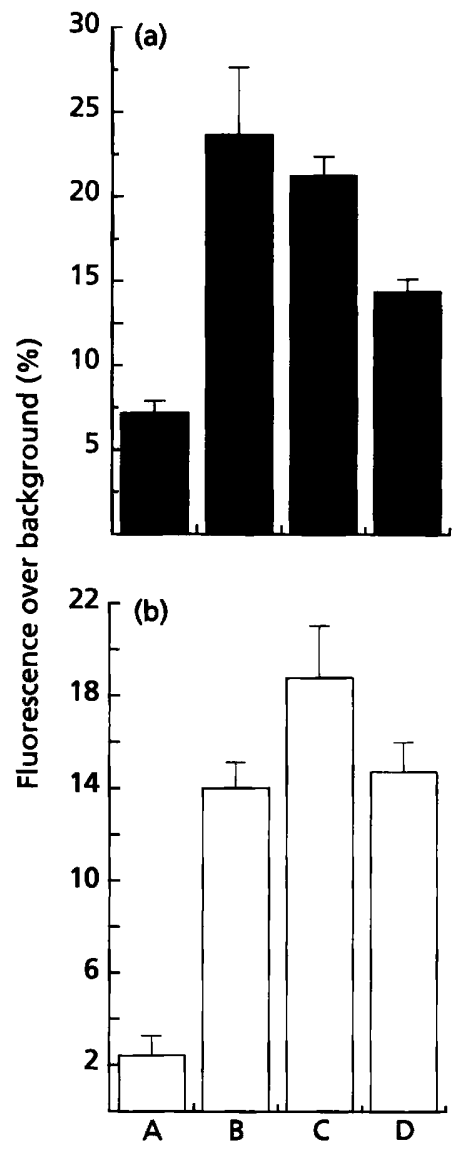

Fig. 4. Comparison of the attachment of fluorescently labelled E. coli HB101 expressing P.69/pertactin RGD, P.69/pertactin RGE or invasin to HEp-2 (a) and $\mathrm{CHO}$ (b) cells. Bacteria were coupled with FITC as described in Methods. Labelled bacteria were centrifuged onto HEp-2 or CHO cells. Cells were incubated for $3 \mathrm{~h}$ at $37^{\circ} \mathrm{C}$ in $10 \% \mathrm{CO}_{2}$. After this time, cells were removed from the tissue culture plate and the number of attached bacteria was analysed by FACS. The columns represent the mean count from four separate wells and the error bars represent the SEM. A, HB101(pMMB66EH); B, HB101(p41869D) (P.69RGD); C, HB101(p41869E) (P.69RGE); D, HB101(pRI203) (invasin protein).

In some experiments, slightly higher numbers of HB101(p41869D) were adherent to cells than HB101(p41869E), whereas in other experiments the reverse was true, but in no instance was there a significant difference in the adhesiveness of the two strains.

\section{Effect of P.69/pertactin on the invasiveness of $E$. coli}

In contrast to the results obtained using Salmonella, P.69/pertactin expression was not found to enhance the invasiveness of HB101 (Fig. 5). The lack of invasiveness was not due to the nature of the assay system as HB101(pRI203), which expresses the Y. pseudotuberculosis invasin protein (which mediates both adhesion and invasion; Isberg \& Falkow, 1996), was highly invasive for HEp-2 cells under the conditions employed (Fig. 5).

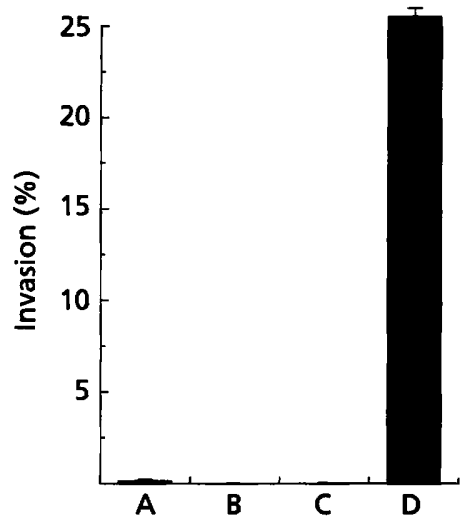

Fig. 5. Effect of P.69/pertactin expression on the invasiveness of $E$. coli for HEp-2 cells. The assay was performed as described in Fig. 2 except that the bacteria were centrifuged onto the cells for $\mathbf{3 0 ~ m i n ~ a t ~ t h e ~ s t a r t ~ o f ~ t h e ~ a s s a y . ~ T h e ~ c o l u m n s ~ r e p r e s e n t ~ t h e ~}$ mean percentage invasion of bacteria from four separate wells and the error bars represent the SEM. Percentage invasion is defined in Fig. 2. A, HB101(pMMB66EH); B, HB101(p41869D) (P.69RGD); C, HB101(p41869E) (P.69RGE); D, HB101(pRI203) (invasin protein).

\section{Factors affecting adhesion mediated by P.69/pertactin}

Since HB101 expressing P.69/pertactin is rendered nonviable by the FITC treatment without destroying enhanced adhesiveness, bacterial viability is not required for adhesion. The influence of a number of other parameters that might affect adherence was analysed; the results are shown in Fig. 6. Frequently centrifugation is employed in adhesion assays to enhance the contact between bacterial and host cells. Usually this augments the adhesiveness of bacteria but is not essential. We found that centrifugation was essential for adhesion of both HB101(p41869E) and HB101(p41869D). Also, an incubation period of at least $3 \mathrm{~h}$ was required to achieve detectable binding of E. coli expressing P.69/pertactin to HEp-2 cells. Interestingly, adhesion was impaired if assays were performed at $4{ }^{\circ} \mathrm{C}$. These results are in contrast to those found with HB101 (pRI203), which does not require centrifugation or incubation for longer than $1 \mathrm{~h}$ to detect adhesion to HEp-2 cells. Also HB101(pRI203) is adherent at $4{ }^{\circ} \mathrm{C}$ (Fig. 6). These data suggest that P.69/pertactinmediated adhesion may require metabolic activity associated with the target eukaryotic cell. Further adhesion assays were performed in the presence of the eukaryotic protein synthesis inhibitor cycloheximide (Fig. 6). Cycloheximide greatly reduced the ability of HB101(p41869D) and HB101(p41869E) but not HB101(pRI203) to adhere to HEp-2 cells.

\section{Adhesion of B. pertussis expressing P.69/pertactin to HEp-2 cells}

Because B. pertussis produces a number of potential adhesins, the effect of mutation in one adhesin gene may be unapparent or underestimated because of compen- 


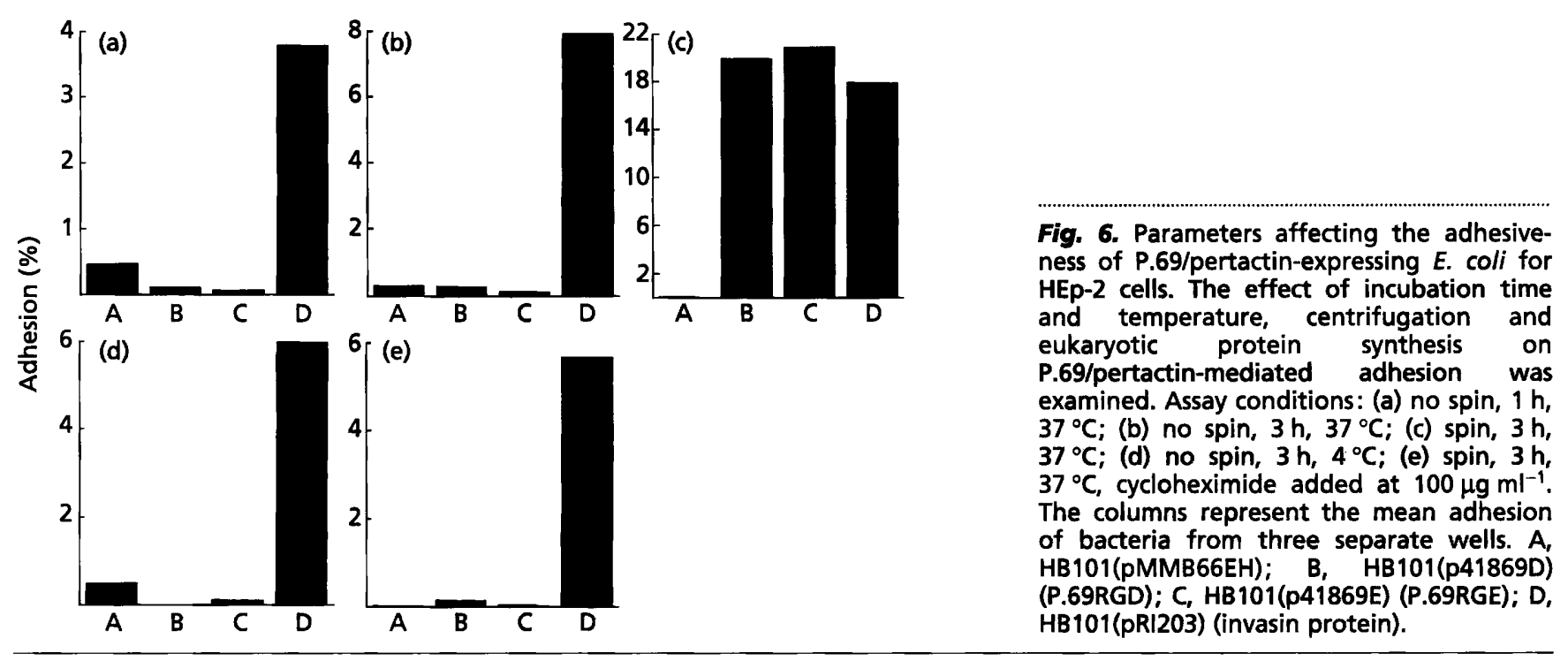

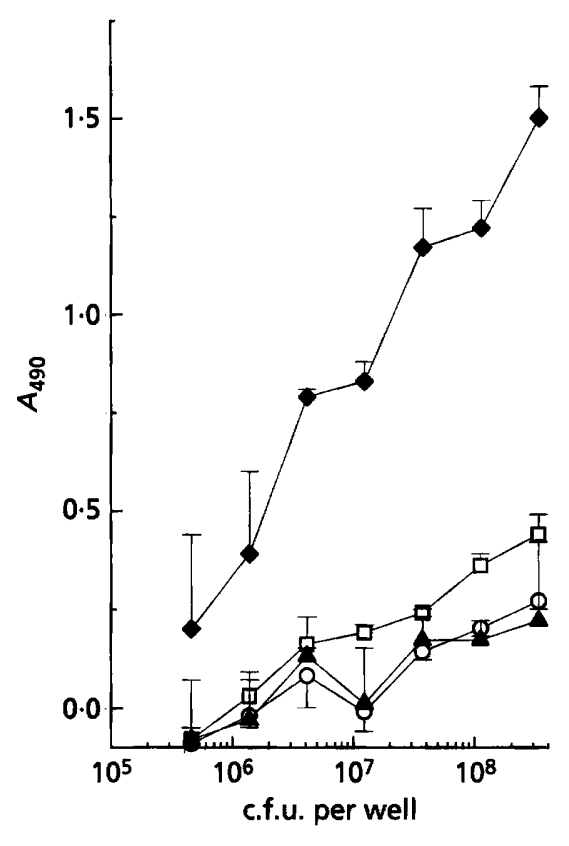

Fig. 7. Effect of P.69/pertactin expression on the adhesiveness of $B$. pertussis bvg. Adhesion of B. pertussis strains to HEp-2 cells was measured by adhesion ELISA as described in Methods. Strains: $\$$, BP536; $\square$, BP347(pMMB66EH); O, BP347(p41869D); $A$ BP347(p41869E). Each point represents the mean absorbance of duplicate tests and the error bars represent the SEM.

sation by other adhesins (Roberts et al., 1991). An alternative approach which may overcome this problem is to take a bvg mutant of B. pertussis, which will not express the majority of the known virulence factors including adhesins, and express the gene for the adhesin under study under the control of a non-bvg-controlled promoter. This would allow the particular adhesin to be studied in isolation in a $B$. pertussis background.

The broad-host-range plasmids $\mathrm{p} 41869 \mathrm{D}$ and $\mathrm{p} 41869 \mathrm{E}$ were transferred into the bvg-negative $B$. pertussis strain
BP347. BP347(p41869D) and BP347(p41869E) expressed levels of surface-associated P.69/pertactin equivalent to the wild-type B. pertussis strain BP536 (results not shown). However, B. pertussis BP347(p41869D) and BP347(p41869E) did not show enhanced adhesiveness or invasiveness to HEp-2 cells compared to BP347(pMMB66EH) in standard adhesion and invasion assays (data not shown). These assays are problematic with $B$. pertussis as detergents cannot be used to lyse the eukaryotic cells because of the exquisite toxicity of detergents for $B$. pertussis. It is difficult to lyse both HEp2 and $\mathrm{CHO}$ cells with water alone. To overcome this problem, we devised a $B$. pertussis cell adhesion ELISA. This not only eliminated the problem of cell lysis, but the 96-well format allowed multiple assays to be performed at one time. This enabled us to determine easily the effect of bacterial numbers on adhesion. As was found in the other assays, expression of neither P.69RGD nor P.69RGE enhanced the adhesiveness of BP347 (Fig. 7). BP347(pMMB66EH), BP347(p41869D) and BP347(p41869E) were much less adhesive to target eukaryotic cells than the parental strain BP536 (Fig. 7). Identical findings were obtained with $\mathrm{CHO}$ cells (data not shown). The number of BP536 cells adherent to HEp-2 cells increased in a dose-dependent fashion. BP536 adhered without centrifugation onto HEp- 2 cells but the number of adherent bacteria increased with centrifugation (data not shown).

\section{DISCUSSION}

The role of P.69/pertactin in mediating the attachment to and invasion of eukaryotic cells was assessed by expressing the full-length pertactin gene in a number of different host bacteria species. The impact of P.69/pertactin expression on adhesiveness or invasiveness was found to differ, depending on the bacterial host cell employed. In Salmonella, P.69/pertactin was found to increase the invasiveness of these naturally invasive bacteria. The impact on invasiveness was greatest with the semi-rough, and normally weakly invasive, $S$. typhimurium strain 
LB5010. The influence of P.69/pertactin on S. typhimurium BRD509, which is naturally highly invasive, was significant but not as great as for LB5010. One probable reason for this is that the rough nature of LB5010 allows P.69/pertactin to be fully exposed on its surface (Strugnell et al., 1992) as it is in B. pertussis, which has short-chain lipopolysaccharide (lipooligosaccharide; Chaby \& Caroff, 1988). In contrast, surface-associated expression of P.69/ pertactin in the normally non-adhesive, non-invasive $E$. coli $\mathrm{K}-12$ strain $\mathrm{HB} 101$ increased the adhesiveness of this strain for HEp-2 and CHO cells but did not influence invasiveness. Thus in E. coli, P.69/pertactin was found to act as an adhesin but not an invasin. This observation suggests that in Salmonella, P.69/pertactin expression is enhancing the invasiveness of strains simply by increasing the efficiency of bacterial/host cell interactions. In fact, we found that pertactin also enhanced the adhesiveness of Salmonella strains (data not shown).

Surface-associated expression of P.69/pertactin did not detectably influence the adhesiveness of the bvg-negative mutant B. pertussis strain BP347. This was initially somewhat surprising since P.69/pertactin has been implicated in B. pertussis adhesion. BP347 has lost bvg activity and thus does not express a number of surface proteins associated with virulence (Weiss et al., 1983). In addition, the genes for some proteins (bvg-repressed genes) are known to be activated in the absence of $b v g$ expression (Knapp \& Mekalanos, 1988). Thus it is possible that the adhesive activity of P.69/pertactin expressed from a non$b v g$-regulated promoter in BP347 may be influenced or suppressed by normally bvg-repressed proteins.

The receptor targeted by P.69/pertactin has not been identified. Evidence using synthetic peptide inhibition of the binding of epithelial cell lines to isolated P.69/ pertactin coated on microtitre plates has implicated a role for the RGD sequence present in mature P.69/pertactin (Leininger $e t$ al., 1991). This would suggest that integrins may be one target receptor for P.69/pertactin on eukaryotic cells. By constructing site-directed mutants of P.69/pertactin we were able to assess the influence on eukaryotic cell adherence of this sequence. Interestingly, E. coli cells expressing a mutant P.69/pertactin where the RGD site in P.69/pertactin had been mutated to RGE were equally as adherent as $E$. coli expressing wild-type P.69/pertactin. Thus P.69/pertactin can clearly mediate bacterial adhesion to eukaryotic cells, even in the absence of a functional RGD motif, indicating that P.69/pertactin may mediate adhesion to target cells by more than one mechanism.

The reported effect of synthetic peptides based on P.69/pertactin on the invasiveness of $B$. pertussis (Leininger et al., 1992) contradicts our finding that P.69/pertactin is not an invasin. If synthetic peptides are affecting P.69/pertactin, it might be that they are inhibiting adhesion mediated by P.69/pertactin and not invasion per se, thereby indirectly affecting the function of another $B$. pertussis factor that promotes invasion.

Analysis of the factors that influence adhesion of bacteria mediated by P.69/pertactin revealed characteristics both typical and atypical of other bacterial adhesins. A common finding with bacterial adhesion is that as long as the adhesin is already present at the start of the assay then bacterial viability is not important, as we found to be the case with P.69/pertactin-expressing E. coli. Centrifugation of bacteria onto host cells was found to be essential for efficient binding by P.69/pertactin-expressing E. coli in our assays. This is unusual; centrifugation will often enhance bacterial adherence but is not usually essential, as we found with the HB101 strain expressing invasin. Centrifugation increases the chance of contact between the bacteria and host cell, thereby reducing the time for maximum binding to occur. In the case of bacteria expressing $p r n$, it is possible that centrifugation overcomes an electrostatic barrier that causes eukaryotic and bacterial cells to repel, allowing P.69/pertactin to act. In wild-type $B$. pertussis this may be accomplished naturally by other, physically longer, adhesins such as FHA or fimbriae that can bring B. pertussis into close enough contact with the host cell to allow P.69/pertactin to act.

Metabolic activity by the target eukaryotic cell is not usually required for bacterial binding as long as the receptor is already present; therefore, attachment can occur at $4{ }^{\circ} \mathrm{C}$ and to killed or fixed cells. Also, bacteria or their purified adhesins can attach to their purified cognate receptor. Our finding that attachment of E. coli expressing P.69/pertactin required metabolically active host cells, and in particular de novo protein synthesis by the eukaryotic cells, was somewhat surprising. This finding is consistent with the prolonged incubation period necessary to observe binding by the P.69/pertactin-expressing strains. One explanation for these findings is that initial contact of P.69/pertactin-expressing E. coli with eukaryotic cells, possibly via pertactin-receptor interactions, results in upregulation of the pertactin receptor. Binding of enteric pathogens, such as enteropathogenic E. coli and Salmonella spp., to eukaryotic cells can activate intracellular signalling pathways in these cells (Biska et al., 1993). Attachment of pertactin to its receptor may induce similar signalling events; this is currently under investigation.

\section{ACKNOWLEDGEMENTS}

M.R., G.D. and P.E. are supported by The Wellcome Trust.

\section{REFERENCES}

Anderson, R., Dougan, G. \& Roberts, M. (1996). Delivery of the pertactin/P.69 polypeptide of Bordetella pertussis using an attenuated Salmonella typhimurium vaccine strain: expression levels and immune response. Vaccine (in press).

Arico, B., Nuti, S., Scarlato, V. \& Rappuoli, R. (1993). Adhesion of Bordetella pertussis to eukaryotic cells requires a time-dependent export and maturation of filamentous hemagglutinin. Proc Natl Acad Sci US A 90, 9204-9208.

Biska, J. B., Galan, J. E. \& Falkow, S. (1993). Signal transduction in the mammalian cell during bacterial attachment and entry. Cell 73, 920.

Chaby, R. \& Caroff, M. (1988). Lipopolysaccharides of Bordetella pertussis endotoxin. In Patbogenesis and Immunity in Pertussis, pp. 
247-271. Edited by A. C. Wardlaw \& R. Parton. Chichester: John Wiley.

Charles, I. G., Dougan, G., Pickard, D., Chatfield, S., Smith, M., Novotny, P., Morrissey, P. \& Fairweather, N. F. (1989). Molecular cloning and characterization of protective outer membrane protein P.69 from Bordetella pertussis. Proc Natl Acad Sci USA 86, 3554-3558.

Charles, I. G., Li, J., Roberts, M., Beesley, K., Romanos, M. Pickard, D. J., Francis, M., Campbell, D., Dougan, G., Brennan, M. J., Manclark, C. R., Jensen, M. A., Heron, I., Chubb, A., Novotny, P. \& Fairweather, N. F. (1991). Identification and characterization of a protective immunodominant b cell epitope of pertactin (P.69) from Bordetella pertussis. Eur J Immunol 21, 1147-1153.

Charles, I., Fairweather, N., Pickard, D., Beesley, J., Anderson, R., Dougan, G. \& Roberts, M. (1994). Expression of the Bordetella pertussis P.69 pertactin adhesin in Escherichia coli: fate of the carboxy-terminal domain. Microbiology 140, 3301-3308.

Cohen, S. M. \& Wheeler, M. W. (1946). Pertussis vaccine prepared from phase 1 cultures grown in fluid medium. Am J Public Health 36, 371-377.

Davis, R. W., Botstein, D. \& Roth, J. R. (1980). Advanced Bacterial Genetics. A Manual for Genetic Engineering. Cold Spring Harbor, NY: Cold Spring Harbor Laboratory.

Friedman, R. L., Nordensson, K., Wilson, L., Akporiaye, E. T. \& Yocum, D. E. (1992). Uptake and intracellular survival of Bordetella pertussis in human macrophages. Infect Immun 60, 4578-4585.

Furste, J. P., Pansagrau, W., Frank, R., Blocker, H., Scholtz, P., Bagdasarian, M. \& Lanka, E. (1986). Molecular cloning of plasmid $\mathrm{RP} 4$ primase region in a multi-host-range tac $P$ expression vector. Gene 48, 119-131.

Hynes, R. O. (1987). Integrins: a family of cell surface receptors. Cell 48, 549-554.

Isberg, R. R. \& Falkow, S. (1996). A single genetic locus encoded by Yersinia pseudotuberculosis permits invasion of cultured epithelial cells. Nature 317, 262-264.

Knapp, S. \& Mekalanos, J. J. (1988). Two trans-acting regulatory genes (vir and mod) control antigenic modulation in Bordetella pertussis. J Bacteriol 170, 5059-5066.

Leininger, E., Roberts, M., Kenimer, J. G., Charles, I. G., Fairweather, N., Novotny, P. \& Brennan, M. J. (1991). Pertactin, an Arg-Gly-Asp-containing Bordetella pertussis surface protein that promotes adherence of mammalian cells. Proc Natl Acad Sci USA 88, 345-349.

Leininger, E., Ewanowich, C. A., Bhargava, A., Peppler, M. S., Kenimer, J. G. \& Brennan, M. J. (1992). Comparative roles of the Arg-Gly-Asp sequence present in the Bordetella pertussis adhesins pertactin and filamentous hemagglutinin. Infect Immun 60, 2380-2385.

Locht, C., Bertin, P., Menozzi, F. D. \& Renauld, G. (1993). The filamentous haemagglutinin, a multifaceted adhesin produced by virulent Bordetella spp. Mol Microbiol 9, 653-660.

Makoff, A. J., Oxer, M. D., Ballantine, S. P., Fairweather, N. F. \& Charles, I. G. (1990). Protective surface antigen p69 of Bordetella pertussis: its characterization and very high level expression in Eschericbia coli. Bio/Tecbnology 8, 1030-1033.

Marwick, M. (1996). Acellular pertussis vaccine hailed for infants. J Am Med Assoc 274, 446-447.

Mool, F. R., Jansen, W. H., Brunings, H., Gielen, H., Van der Heide, H. G. J., Walvoort, H. C. \& Guinee, P. A. M. (1992).
Construction and analysis of Bordetella pertussis mutants defective in the production of fimbriae. Microb Pathog 12, 127-135.

Novotny, P., Chubb, A. P., Cownley, K. \& Charles, I. G. (1991). Biologic and protective properties of the $69-\mathrm{kda}$ outer membrane protein of Bordetella pertussis: a novel formulation for an acellular pertussis vaccine. J Infect Dis 164, 114-122.

Poland, G. A. (1996). Acellular pertussis vaccines: new vaccines for an old disease. Lancet 347, 209-210.

Rappuoli, R. (1994). Pathogenicity mechanisms of Bordetella. Curr Top Microbiol Immunol 192, 319-336.

Relman, D. A., Domenighini, M., Tuomanen, E., Rappuoli, R. \& Falkow, S. (1989). Filamentous hemagglutinin of Bordetella pertussis: nucleotide sequence and crucial role in adherence. Proc Natl Acad Sci US A 86, 2637-2641.

Relman, D., Tuomanen, E., Falkow, S., Golenbock, D. T., Saukkonen, K. \& Wright, S. D. (1990). Recognition of a bacterial adhesin by an integrin: macrophage $\mathrm{Cr} 3(\alpha(\mathrm{m}) \beta 2, \mathrm{CD} 11 \mathrm{~b} / \mathrm{CD} 18)$ binds filamentous hemagglutinin of Bordetella pertussis. Cell 61, 1375-1382.

Roberts, M., Fairweather, N. F., Leininger, E., Pickard, D., Hewlett, E. L., Robinson, A., Hayward, C., Dougan, G. \& Charles, I. G. (1991). Construction and characterization of Bordetella pertussis mutants lacking the vir-regulated P.69 outer membrane protein. Mol Microbiol 5, 1393-1404.

Roberts, M., Tite, J. P., Fairweather, N. F., Dougan, G. \& Charles, I. G. (1992). Recombinant P.69/pertactin: immunogenicity and protection of mice against Bordetella pertussis infection. Vaccine 10, 43-48.

Roberts, M., Cropley, I., Chatfield, S. \& Dougan, G. (1993). Protection of mice against respiratory Bordetella pertussis infection by intranasal immunization with P.69 and FHA. Vaccine 11, 866-872.

Romanos, M. A., Clare, J. J., Beesley, K. M., Rayment, F. B., Ballantine, S. P., Makoff, A. J., Dougan, G., Fairweather, N. F. \& Charles, I. G. (1991). Recombinant Bordetella pertussis pertactin (p69) from the yeast Pichia pastoris: high-level production and immunological properties. Vaccine 9, 901-906.

Sandros, J. \& Tuomanen, E. (1993). Attachment factors of Bordetella pertussis: mimicry of eukaryotic cell recognition molecules. Trends Microbiol 1, 192-196.

Shahin, R. D., Brennan, M. J., Li, Z. M., Meade, B. D. \& Manclark, C. R. (1990). Characterization of the protective capacity and immunogenicity of the 69-kd outer membrane protein of Bordetella pertussis. J Exp Med 171, 63-73.

Strugnell, R., Dougan, G., Chatfield, S., Charles, I., Fairweather, N., Tite, J., Jing Li, L., Beesley, J. \& Roberts, M. (1992). Characterization of a Salmonella typhimurium aro vaccine strain expressing the P.69 antigen of Bordetella pertussis. Infect Immun 60, 3994-4002.

Tuomanen, E. \& Weiss, A. (1985). Characterization of two adhesins of Bordetella pertussis for human ciliated respiratory-epithelial cells. $J$ Infect Dis 152, 118-125.

Weiss, A. A., Hewlett, E. L., Myers, G. A. \& Falkow, S. (1983). Tn5induced mutations affecting virulence factors of Bordetella pertussis. Infect Immun 42, 33-41.

Received 3 May 1996; revised 18 July 1996; accepted 22 July 1996. 